\title{
Improving and monitoring the magnetic pulse welding process between dissimilar metals
}

\author{
Joerg Bellmann ${ }^{1,2}$ (D) $\cdot$ Sebastian Schettler ${ }^{1,3} \cdot$ Sebastian Schulze ${ }^{1} \cdot$ Markus Wagner $^{1} \cdot$ Jens Standfuss $^{1}$. \\ Martina Zimmermann ${ }^{1,3} \cdot$ Eckhard Beyer $^{2} \cdot$ Christoph Leyens $^{1,3}$
}

Received: 11 July 2020 / Accepted: 3 October 2020 / Published online: 24 October 2020

(C) The Author(s) 2020

\begin{abstract}
Conventional fusion welding of dissimilar metals is often limited due to the different thermo-physical properties of the joining partners. In consequence, brittle intermetallic phases (IMC) can occur. Utilizing a pressure welding process like magnetic pulse welding (MPW) reduces the risk of IMCs significantly. Furthermore, this welding process has an outstanding short process duration in the range of a few microseconds, which makes it predestined for mass production. At the same time, this advantage challenges the process observation, inline-quality assurance hardware, and the design of the tool coils. The paper presents two strategies for reducing the energy input during MPW to increase the tool coil lifetime. The first approach, the introduction of a reactive nickel interlayer between steel and aluminum, leads to a significant welding energy reduction. Compared to aluminum samples joined by laser welding, the load-bearing capability of the resulting hybrid MPW driveshaft samples is higher in static torsion tests and similar in cyclic tests. The second approach is based on a novel process monitoring system that helps to analyze the characteristic light emission. The capability of the process monitoring system is presented on the example of a MPW-joined multimaterial part made of stainless steel, aluminum, and copper.
\end{abstract}

Keywords Magnetic pulse welding $\cdot$ Dissimilar metal welding $\cdot$ Torsion test $\cdot$ Tightness test $\cdot$ Process monitoring

\section{Nomenclature \\ Symbol; Parameter, abbreviation \\ C Capacity, collision point \\ E Charging energy \\ $f_{\text {discharge }}$ Discharge frequency \\ $g \quad$ Initial joining gap}

Recommended for publication by Commission III - Resistance Welding, Solid State Welding, and Allied Joining Process

Joerg Bellmann

joerg.bellmann@iws.fraunhofer.de

1 Fraunhofer IWS Dresden, Winterbergstr. 28, 01277 Dresden, Germany

2 Institute of Manufacturing Science and Engineering, Technische Universität Dresden, George-Baehr-Str. 3c, 01062 Dresden, Germany

3 Institute of Materials Science, Technische Universität Dresden, Helmholtzstr. 7, 01069 Dresden, Germany

$\begin{array}{ll}I & \text { Discharge current } \\ I_{f} & \text { Intensity of the impact flash } \\ I_{\max } & \text { Maximum discharge current } \\ l_{\text {weld }} & \text { Length of welded zone } \\ L_{i} & \text { Inner inductance of the pulse generator } \\ l_{w} & \text { Working length } \\ p_{m} & \text { Magnetic pressure } \\ R_{i} & \text { Inner resistance of the pulse generator } \\ s_{f} & \text { Wall thickness of the flyer tube } \\ \mathrm{s}_{p} & \text { Wall thickness of the parent tube } \\ S & \text { High voltage switch } \\ t & \text { Time } \\ t_{i} & \text { Impact time } \\ t_{\mathrm{f}, \text { start }} & \text { Flash appearance time } \\ U_{\mathrm{max}} & \text { Maximum charging voltage } \\ v_{c} & \text { Axial collision point velocity } \\ v_{i} & \text { Impact velocity } \\ v_{i, r} & \text { Radial impact velocity } \\ \beta & \text { Collision angle } \\ \gamma & \text { Damping coefficient of } I(t)\end{array}$




\section{Introduction}

Technical structures often consist of dissimilar metals, in order to meet for example, lightweight requirements, take advantage of special material properties and enable cost reduction by replacement of an expensive material. Thus, the demand for suitable joining technologies grows. Form- or force-fit joints are successfully applied in many cases. Nevertheless, there are applications were a metallurgical joint is required, e.g., to obtain a high structural strength or low electrical contact resistance. However, conventional fusion welding processes often reach their technological limits when welding dissimilar metals due to the formation of brittle intermetallic phases (IMP). With pressure welding technologies, the heat input and the IMP formation, respectively, can be reduced significantly, enabling the production of durable joints. The necessary pressure at the weld interface can be generated, for example, by a controlled high-speed collision between the joining partners. There are certain strategies to accelerate the first workpiece called "flyer" up to several hundred meters per second and arrange the collision with the fixed workpiece called "parent." The pressure can be generated by Lorentz forces that act between a coil and the workpiece (magnetic pulse welding-MPW [1]), the detonation of an explosive (explosive welding-EXW [2]), the vaporization of foils (vaporizing foil actuator-VFA [3]), or pulsed lasers (laser impact welding - LIW [4]). MPW is suitable for smaller structures with wall thicknesses of the order of some millimeters. It requires a sufficient electrical conductivity of the flyer to induce eddy currents and build up the magnetic pressure. If these boundary conditions are fulfilled, the process is predestined for the line production of dissimilar metal joints with a good repeatability. Nevertheless, by the very nature of the process, the thermo-mechanical loading on the tool coils limits their lifetime in certain applications [5]. Furthermore, the identification of suitable welding parameters and the inline quality assurance are difficult to realize due to the process durations in the range of a few microseconds, the intense magnetic fields and the destructive forces that occur in the vicinity of the impact zone and that act on any sensors located there.

This paper presents two strategies to overcome these issues. It is divided into two parts:

1. Explanation of the theory of the MPW process and existing methods for an improved bond formation. At the same time, the phenomena of the impact flash and its usability for the process observation are described.

2. Transfer of the theoretical findings to two different joining applications. Tubular parts made of different steel, aluminum, and copper alloys are welded and undergo specific test scenarios. Finally, conclusions are drawn regarding the applicability of the presented methods.

\section{Theory}

\subsection{MPW process}

MPW is a two-stage process. In the first step, an electromagnetic forming process accelerates the first joining partner called "flyer," which can reach velocities up to several hundred meters per second during the high-speed forming process. In the second step, the flyer collides and rolls over on the stationary joining partner called "parent."

Collision welding occurs under specific rolling or impact conditions. They are illustrated in Fig. 1a and depend on the involved materials. There are three kinetic values at the propagating collision point $\mathrm{C}$ that characterize the rolling movement of the flyer on the parent: $v_{i}, v_{c}$, and $\beta$. They are linked by the expression in Eq. 1. During the parameter identification of the MPW process, these collision conditions have to be adjusted properly within the welding window, as depicted in Fig. 1b, to ensure a good weld quality. At this point, it should be noted that classical welding windows in the $v_{c}$ - $\beta$-plane do
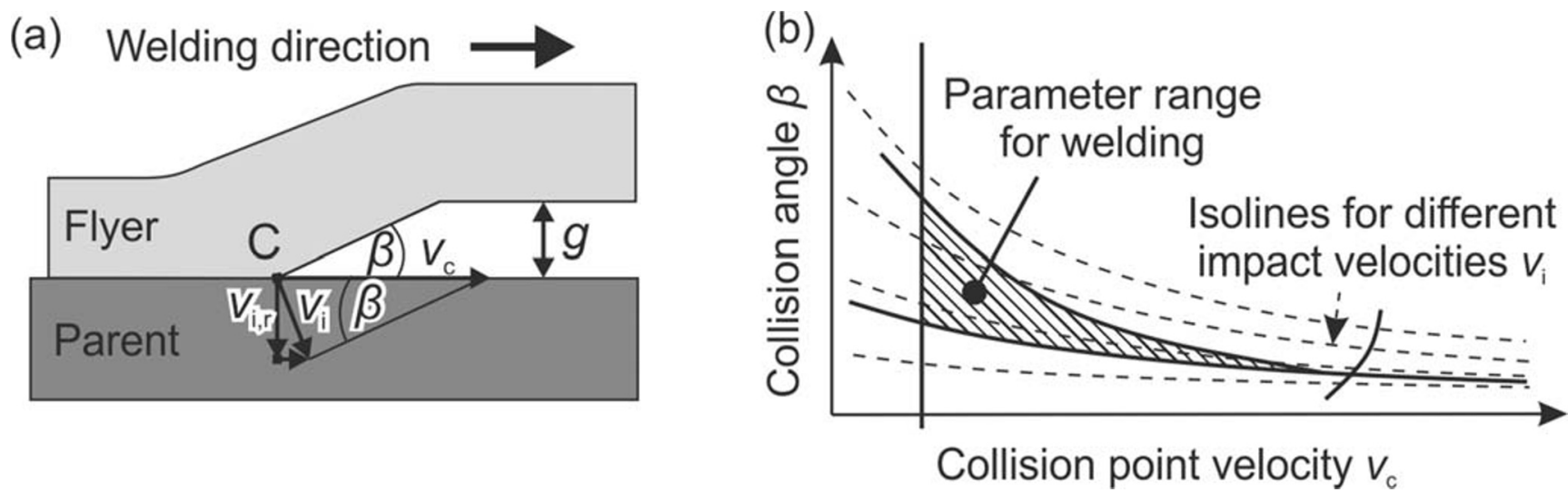

Fig. 1 a Definition of the kinetic collision conditions at the propagating collision point $\mathrm{C}$ in accordance with [6] and $\mathbf{b}$ schematic welding window for collision welding processes according to [7] 

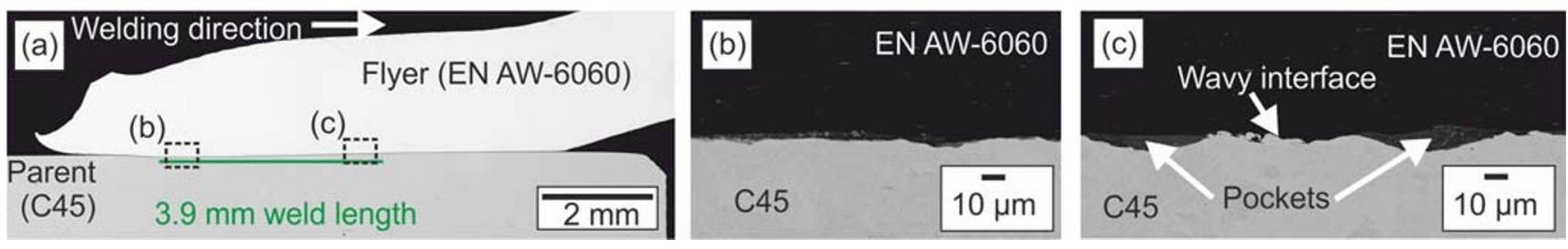

Fig. 2 Cross sections of a MPW weld seam with a severe plastic deformation of the flyer with initially constant wall thickness and details of the weld interface b approximately $0.5 \mathrm{~mm}$ and $\mathbf{c} 3.5 \mathrm{~mm}$ behind the weld seam beginning according to [11]

not consider the surface properties or the wall thickness of the joining partners. They are typically used for EXW processes since $v_{c}$ is directly linked to the detonation velocity of the explosive, one of the key process parameters. Due to the nature of the MPW process, $v_{i}$ is easier to access by wellestablished photonic Doppler velocimetry $[8,9]$ than $v_{c}$ and, thus, welding windows in the $v_{i}-\beta$-plane are common for MPW, too. In contrast to EXW, the movement of the collision point is not stationary due to the time- and position-dependent distribution of the magnetic field and other geometrical parameters. Thus, the welding process cannot be characterized by a single point in the welding window but appears as a line or as a mean value [10]. At the same time, the resulting weld interface changes along the propagation of the collision front, see Fig. 2. The waviness increases in welding direction and the resulting pockets are often filled with material of both joining partners in a non-equilibrium ratio [11]. There are many hints and proofs for the existence of high temperatures and cooling rates at the weld interface during the collision [12, 13], for example, witnessed by the formation of metastable phases as well as ultra-fine grained structures [7, 14].

$\frac{\sin (2 \beta)}{2}=\frac{v_{i}}{v_{c}}$

The severe plastic deformation at collision point $\mathrm{C}$ is responsible for the ejection of a cloud of particles $(\mathrm{CoP})$ and/or a jet in form of a massive material flow [15]. High-speed images revealed a $\mathrm{CoP}$ or jet velocity of several kilometers per second, depending on the surrounding medium [16]. The density of the gas in the joining gap determines the temperature during its shock compression, too [17]. Recent studies indicated a visible process glare, even in the absence of a surrounding medium in vacuum-like conditions [11]. It is attributed to the compression of the CoP itself, since the estimated temperatures based on the color temperature increase for smaller collision angles $\beta$ [18]. It can exceed the vaporization temperature of the involved materials since temperatures in the range of $5600 \mathrm{~K}$ were measured [19]. Thus, the thermal interaction of the $\mathrm{CoP}$ with the surfaces of the joining partners contributes to the surface activation before being pressed together. This supports the theory of a liquid state bonding phenomenon [20].

\subsection{Measurement techniques for MPW}

The control of the collision conditions is of great importance for the production of high-quality welds, especially if small collision angles and high process temperatures shall be achieved. Adjusting the machine-related and geometrical parameters can be a time-consuming process if no suitable strategies for the measurement of these conditions are available. Bellmann et al. [21] presented certain established and new measurement strategies, whereby optical methods are preferred due to the short process durations and intense magnetic fields that would disturb the signals from conventional electrical sensors. The patented flash measurement system [22, $23]$ is utilized to monitor the characteristic impact flash and determine the radial impact velocity $v_{i, r}$ and the axial collision point velocity $v_{\mathrm{c}}$, see Fig. $3 \mathrm{a}$ and $\mathrm{b}$, respectively [6]. The process glare occurs at $t_{\mathrm{f} \text {,start }}$, approximately $0.5 \mu \mathrm{s}$ after the initial impact $t_{i}[6]$ as depicted in Fig. $3 \mathrm{c}$ and its maximum intensity can serve as a necessary welding criterion after calibration [24]. Figure 4 illustrates the integration of the flash measurement system within the experimental setup.
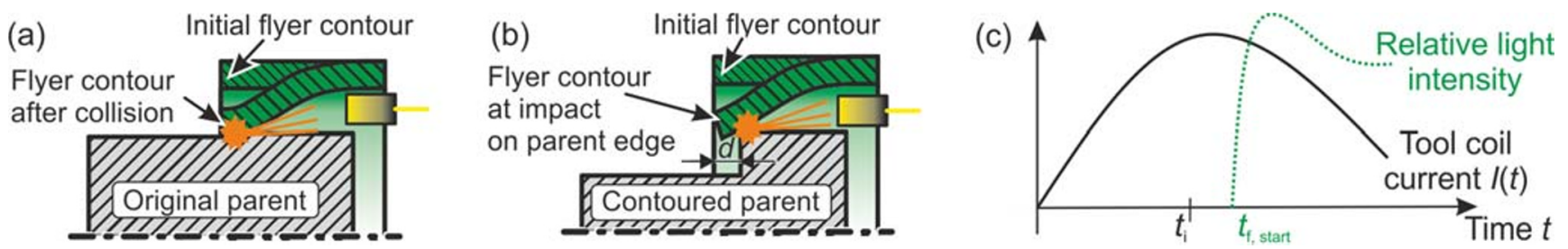

Fig. 3 Application of the flash measurement system next to the joining zone for the determination of a the impact velocity $v_{i}, \mathbf{b}$ the axial collision point velocity $v_{c}$, and $\mathbf{c}$ exemplary course of the relative light intensity in relation to the impact time $t_{i}$ and the tool coil current $I(t)$ 
a)

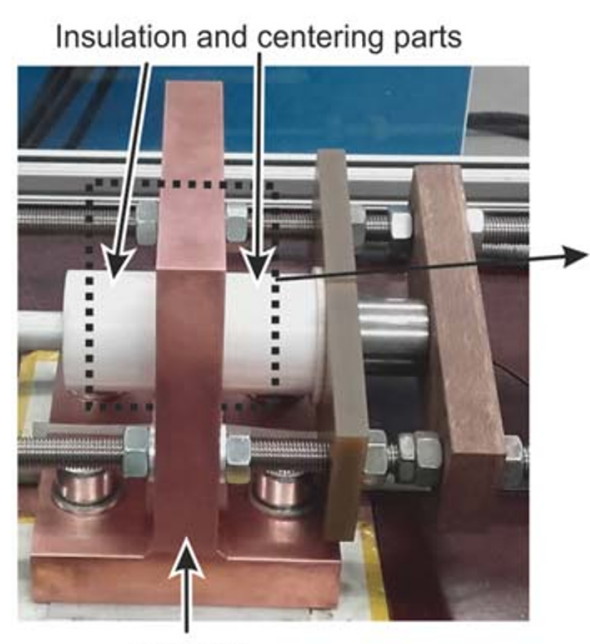

Tool coil

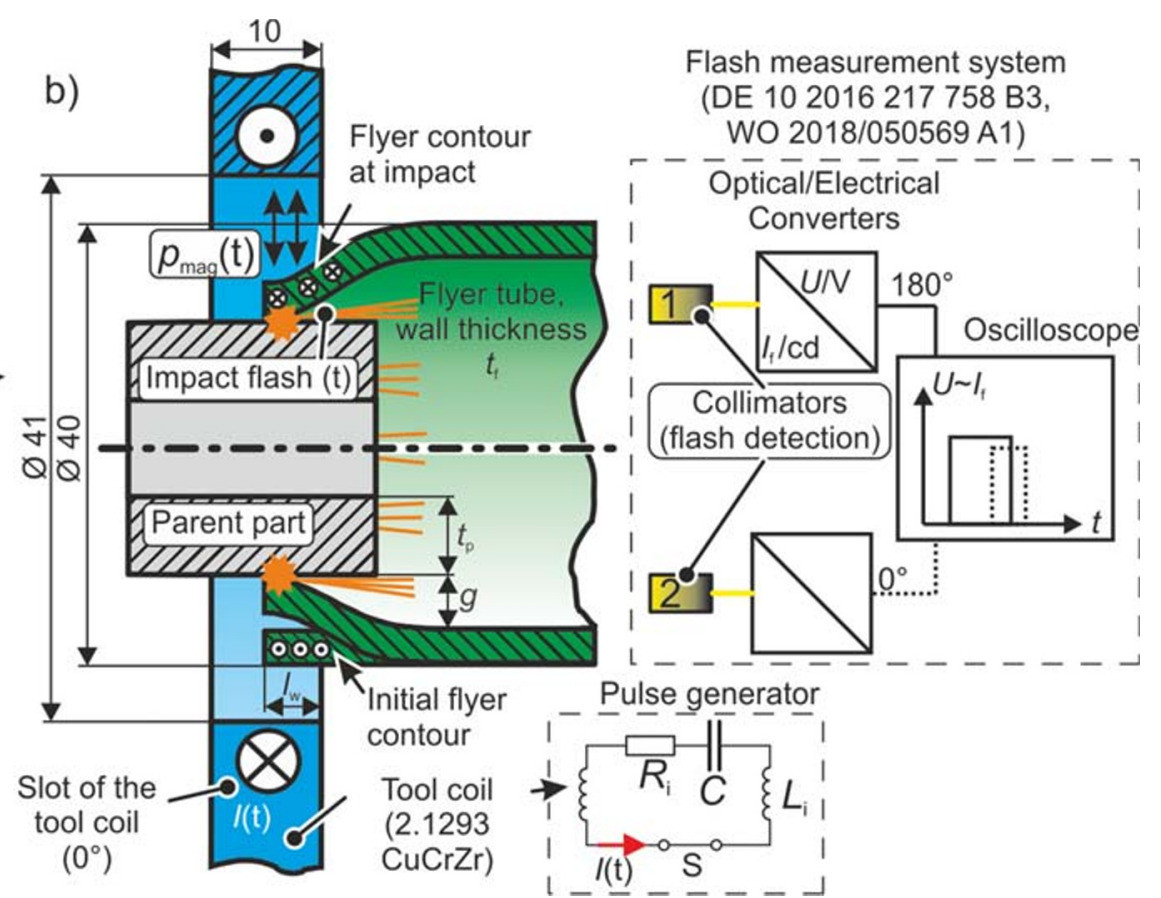

Fig. 4 a MPW setup and $\mathbf{b}$ section view for geometrical definitions and positioning of the flash measurement system (without insulation and centering parts, all values in $\mathrm{mm}$ )

\subsection{Strategies for an improved bond formation}

During MPW, the tool coils are exposed to mechanical and thermal shock loading due to the sudden rise of the magnetic pressure and high current densities, respectively. Depending on the geometry and material of the flyer part, as well as the cycle time of the welding process, softening and unwanted deformations can occur in the working zone of the tool coil. This leads to a change in the electromagnetic forming behavior and might affect the welding result. Furthermore, the process efficiency decreases in case the distance between the coil and the flyer increases [25]. It is therefore recommended to reduce the tool coil current as much as possible, following these two strategies for example:

1 Application of an additional heat source at the weld interface between the joining partners [26]. The chemical reaction of some combinations of alloys is exothermic and can be utilized for example in reactive multilayer materials [27]. During MPW of aluminum and steel, an interlayer of nickel on the steel parent can lower the necessary impact velocity of the flyer and the tool coil current for a circumferential weld seam [25].

2 Reduction of the necessary impact velocity by supporting the liquid state bonding mechanism. This effect is enhanced at smaller collision angles which can be achieved by adjusting the acceleration distance $g$, the working length $l_{\mathrm{w}}$, the discharging frequency $f_{\text {discharge, }}$ and the charging energy E. Compared to larger collision angles, the compression of the CoP and thus, the temperature in the joining gap are increased. The flash measurement system helps to identify these conditions and reduces the experimental effort for the optimization of these four independent parameters [24], while the influence of the wall thickness is taken into account at the same time [28].

\section{Experimental procedure}

The aforementioned strategies are realized by the experimental setup shown in Fig. 4. The setup includes the pulse generator MPW 50/25 from the company Bmax (Toulouse,

Table 1 Characteristic of the RLC-circuit with the deployed Bmax pulse generator MPW 50/25

\begin{tabular}{|c|c|c|}
\hline Parameter & Unit & Value \\
\hline Capacitance $C$ & $\mu \mathrm{F}$ & 160 \\
\hline Inductance $L_{\mathrm{i}}^{\mathrm{a}}$ & $\mathrm{nH}$ & 372 \\
\hline Maximum charging energy & $\mathrm{kJ}$ & 32 \\
\hline Maximum charging voltage $U_{\max }$ & $\mathrm{kV}$ & 20 \\
\hline Applied charging energy $E$ & $\mathrm{~kJ}$ & $\begin{array}{r}2.0 \ldots \\
11.5\end{array}$ \\
\hline Discharge frequency ${ }^{\mathrm{a}} f_{\text {discharge }}$ & $\mathrm{kHz}$ & $\sim 21$ \\
\hline Damping coefficient $\gamma^{\mathrm{a}}$ & $1 / \mathrm{s}$ & 16,500 \\
\hline
\end{tabular}

${ }^{\mathrm{a}}$ For the complete RLC-circuit with tool coil and workpieces 
Table 2 Geometrical parameters and materials for both applications

\begin{tabular}{|c|c|c|c|}
\hline & Unit & Driveshaft & Multi-material part \\
\hline Strategy for energy reduction & & $5-\mu \mathrm{m}$ nickel interlayer & Small collision angle \\
\hline Flyer tube material & & Aluminum alloy EN AW-6060 T66 [29] & $\begin{array}{l}\text { Aluminum alloy EN AW-1050 [30] } \\
\text { /copper alloy Cu-ETP (CW004A) [31] }\end{array}$ \\
\hline Flyer tube thickness $t_{\mathrm{f}}$ & $\mathrm{mm}$ & 2 & 1 \\
\hline Flyer tube outer diameter & $\mathrm{mm}$ & 40 & 40 \\
\hline Parent material & & $\begin{array}{l}\text { Case hardening steel C45, normalized } \\
\quad(1.0503) \text { [32], mean roughness index } R_{a}=1\end{array}$ & Stainless steel X6CrNiTi18-10 (1.4541) [33] \\
\hline Parent thickness $t_{\mathrm{p}}$ & $\mathrm{mm}$ & 11.5 (rod with inner centering borehole) & 2 (tube) \\
\hline Joining gap $g$ & $\mathrm{~mm}$ & 1.5 & 1 \\
\hline Working length $l_{\mathrm{w}}$ & $\mathrm{mm}$ & 6 & 6 \\
\hline
\end{tabular}

France) with its characteristic values summarized in Table 1. During the experiments, the tool coil current $I(t)$ is measured with a Rogowski current probe CWT $3000 \mathrm{~B}$ from the company Power Electronic Measurements Ltd. The sensors of the flash measurement system have optical access to the joining gap and are placed parallel to the tube axis with approximately $30 \mathrm{~mm}$ distance to the initial point of impact. The specific geometrical parameters and materials for two applications are listed in Table 2. The axisymmetric driveshaft-like parts are designed to transmit torsional loads. Considering lightweight aspects, the part which is typically made completely out of steel is replaced by a multi-material part consisting of two heat-treatable steel rods with a central aluminum tube. Due to the increased wall thickness of the aluminum tube, the stiffness of the tube increases, too. At the same time, the risk for buckling is decreased. In the present study, some of the

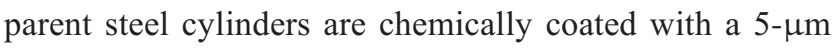
thick nickel interlayer.

The multi-material part was created at the Research Neutron Source Heinz Maier-Leibnitz (FRM II). For the envisioned application in cryostats operating at temperatures down to $1.5 \mathrm{~K}$, modified geometries were used. The part consists of three different materials. Aluminum and copper have a higher electrical conductivity and a lower mechanical strength compared to stainless steel. These properties predestine both parts to act as the flyer tubes [34]. They are accelerated one after another on the stationary parent part. Due to the differences in the density and yield strength, as well as electrical conductivity and magnetic permeability, an adjustment of the charging energy is performed for both materials. At first, the aluminum flyer tube is welded to the stainless steel tube with different impact velocities until the peel test reveals a weld length that is at least twice as big as the wall thickness [21]. Secondly, the same procedure is applied for the combination copper and stainless steel. During all experimental tests, a steel mandrel is positioned in the stainless steel tube to reduce the unwanted deformations [35, 36]. Furthermore, the inner step on the flyer parts is removed at the positions of the coils slot $\left(0^{\circ}\right)$ and at the opposite location $\left(180^{\circ}\right)$ to ensure optical access of the flash detection sensors to the joining gap, see Fig. 7. Based on earlier test series, the joining gap $g$ is set to $1 \mathrm{~mm}$ and the working length $l_{\mathrm{w}}$ equals $6 \mathrm{~mm}$ during all tests [24] in order to obtain a small collision angle. After MPW, $\mathrm{X}$-ray computed tomography of both joining zones is performed with $200 \mathrm{kV}$ and $300 \mu \mathrm{A}$ at the system FF35 CT from the company YXLON.

\section{Results and discussion}

The driveshaft-like assembly is shown in Fig. 5. A charging energy of $8 \mathrm{~kJ}$ was needed to achieve a circumferential weld seam. The application of a $5-\mu \mathrm{m}$ nickel interlayer has enabled a reduction to $5.8 \mathrm{~kJ}$ while the weld seam length at the $180^{\circ}$ position was even increased from 3.5 to $5.9 \mathrm{~mm}$ [25]. An additional experiment was performed, where the nickel interlayer has been mechanically removed prior to MPW along the first $5 \mathrm{~mm}$ behind the initial point of impact. The interlayer resulted in a welding formation at the position, where no weld seam was generated during the direct joining of aluminum and steel, see Fig. 5h.

Samples that included a continuous nickel interlayer (Fig. 5e) and laser beam welded (LBW) driveshafts with the same geometrical dimensions, but using aluminum instead of steel rods, were tested under static and dynamic torsional loadings with three and six test specimens, respectively, as described in [25]. The strength of the joints in megapascal $(\mathrm{MPa})$ are not directly comparable due to the differences in the distribution of the shear stresses and the sectional areas of the weld seams for the laser-welded butt joint with two millimeters weld seam depth and the magnetic pulse welded overlap configuration with more than $4 \mathrm{~mm}$ weld seam length. Nevertheless, the overall load bearing capability of the complete sample in Newtonmeter $(\mathrm{Nm})$ can be compared 

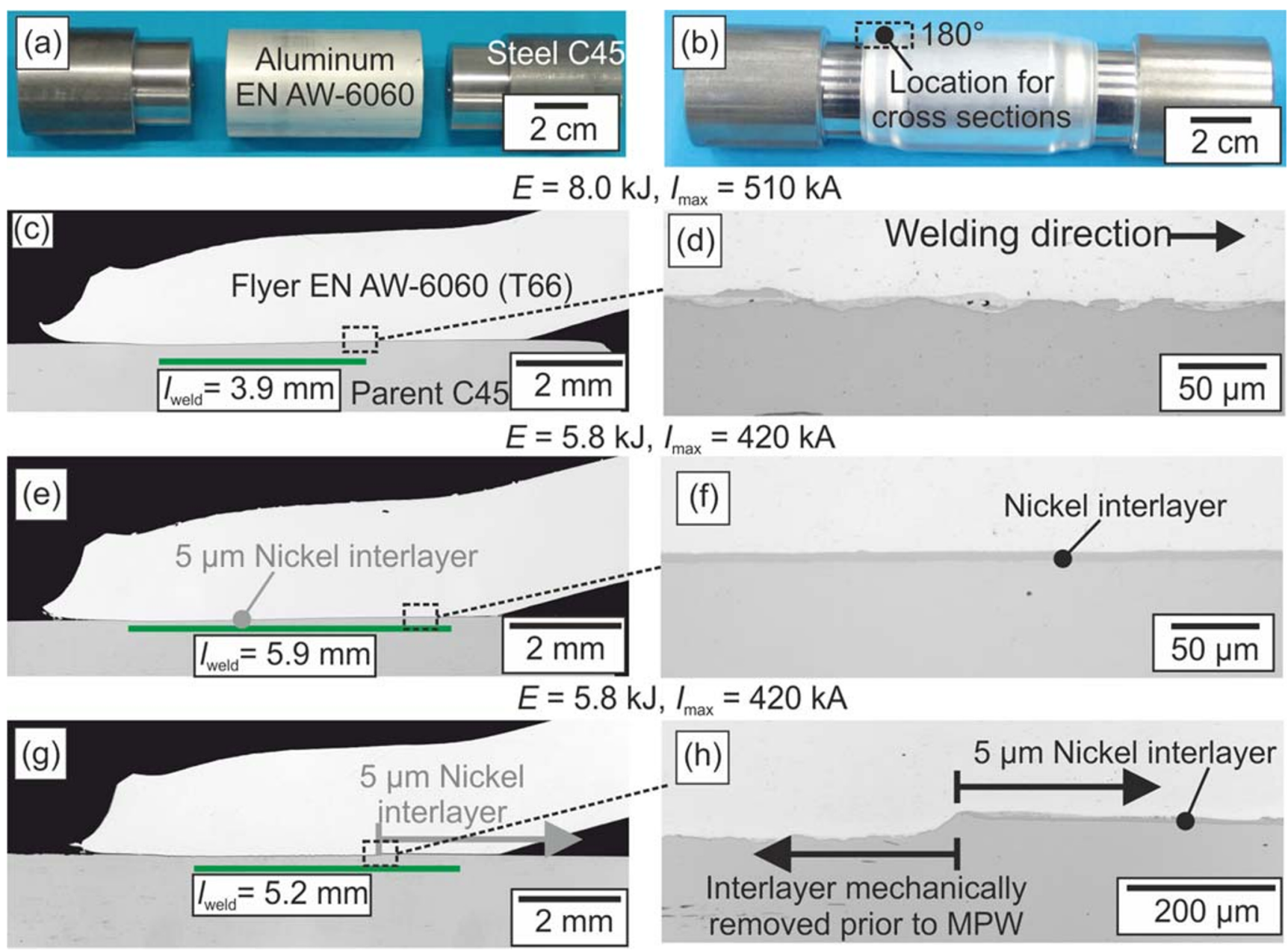

Fig. 5 Hybrid driveshaft $\mathbf{a}$ before MPW and $\mathbf{b}$ after MPW and cross sections for $\mathbf{c}, \mathbf{d}$ direct joining of aluminum and steel, $\mathbf{e}, \mathbf{f}$ application of a continuous nickel interlayer, and $\mathbf{g}, \mathbf{h}$ application of a nickel interlayer beginning $5 \mathrm{~mm}$ behind the initial point of impact

with the MPW samples due to the identical geometrical dimensions of the driveshafts. MPW resulted in an increased static load bearing capability of $737 \mathrm{Nm}$ [37] compared to the laser welded specimens with $558 \mathrm{Nm}$, since the heat-affected zone was significantly reduced with MPW. Furthermore, MPW lead to an increased amplitude of the alternating torsional load for a failure probability of $50 \%$ of $127 \mathrm{Nm}$ compared to $113 \mathrm{Nm}$ for LBW specimens. Failure occurred within the weld seam at the laser welded samples and next to the weld seam in the tube material for magnetic pulse welded parts. Thus, the determination of the weld strength is not possible for MPW in this case.

For the multi-material part, the geometrical boundary conditions were kept constant and thus, the influence of the impact velocity was studied and compared for both material combinations, see Table 3 . The radial impact velocity was calculated based on the assumptions that the flyer was accelerated steadily and the flash occurred $0.5 \mu$ s after the initial impact in analogy with [6]. Obviously, the flash started earlier for high charging energies and thus, the radial impact velocity increased. Normally, the flyer acceleration and impact velocity, respectively, is lower at the position of the slot of the tool coil $\left(0^{\circ}\right)$ due to the reduced magnetic pressure [21]. However, in tests \#1 and \#3, the opposite effect was observed. Probably, a misalignment of the cut grooves in the workpieces that are indicated in Fig. 7 and ensure the optical access for the sensors to the impact flash was responsible for this abnormal behavior. Nevertheless, the results revealed a comparatively low impact velocity for the weld formation, which is explainable by the targeted collision kinetics with small impact angles [38]. Using copper as flyer material a higher charging energy is required due to the increased material density and strength. Therefore, the impact velocity, that enabled a weld formation between aluminum and steel, was not sufficient for MPW of copper to steel. Increasing the charging energy to $11.5 \mathrm{~kJ}$ and the radial impact velocity to $204 \mathrm{~m} / \mathrm{s}$ resulted in a circumferential weld.

After removing the inner mandrel from the parent tube, the part underwent non-destructive X-ray computed tomography to identify the deformations due to the high-speed impact. Figure 6 shows the pronounced deformation of the accelerated flyer edge, its indentation into the parent tube and, finally, a 
Table 3 Effect of the charging energy on the measured starting time of the impact flash and the calculated radial impact velocity, while each data point represents one trial due to a limited number of samples

\begin{tabular}{|c|c|c|c|c|c|c|c|c|}
\hline \multirow[t]{2}{*}{$\begin{array}{l}\text { Material } \\
\text { combination }\end{array}$} & \multirow[t]{2}{*}{$\begin{array}{l}\text { Test number } \\
\#\end{array}$} & \multirow[t]{2}{*}{ Circumferential weld } & \multirow[t]{2}{*}{$\begin{array}{l}\text { Charging } \\
\text { energy } E \\
\text { kJ }\end{array}$} & \multirow[t]{2}{*}{$\begin{array}{l}\text { Maximum tool } \\
\text { coil current } I(t) \\
\text { kA }\end{array}$} & \multicolumn{2}{|c|}{$\begin{array}{l}\text { Starting time } \\
\text { of the flash } t_{\mathrm{f}, \mathrm{star}} \\
\mu \mathrm{s}\end{array}$} & \multicolumn{2}{|c|}{$\begin{array}{l}\text { Calculated radial } \\
\text { impact velocity, } v_{i, r} \\
\mathrm{~m} / \mathrm{s}\end{array}$} \\
\hline & & & & & $180^{\circ}$ & $0^{\circ}$ & $180^{\circ}$ & $0^{\circ}$ \\
\hline $\mathrm{Al}-\mathrm{St}$ & 1 & Yes & 2.0 & 251 & 19.0 & 18.1 & 108 & 114 \\
\hline $\mathrm{Al}-\mathrm{St}$ & 2 & Yes & 2.9 & 312 & 17.2 & 17.7 & 120 & 116 \\
\hline $\mathrm{Al}-\mathrm{St}$ & 3 & Yes & $3.9^{\mathrm{b}}$ & 360 & 14.9 & 13.5 & 139 & 154 \\
\hline $\mathrm{Cu}-\mathrm{St}$ & 4 & No & 8.0 & 504 & 14.6 & 18.3 & 142 & 112 \\
\hline $\mathrm{Cu}-\mathrm{St}$ & 5 & Yes & $11.5^{\mathrm{b}}$ & 630 & 9.3 & 10.3 & 227 & 204 \\
\hline
\end{tabular}

${ }^{\mathrm{b}}$ Final welding parameters

slight reduction of the inner parent tube diameter, although a mandrel was used during MPW.

The applied X-ray computed tomography was not able to distinguish between welded and non-welded areas with a gap between both joining partners, probably because of the insufficient local resolution. Thus, polished cross sections at four different positions were prepared and analyzed by optical microscopy, see Fig. 7. All weld seams were more than three times longer than the flyer wall thickness. The positions that were placed at the slot of the tool coil during MPW $\left(0^{\circ}\right)$ exhibited shorter weld seams since the impact velocity was reduced and the collision angle tended to increase. At the opposite position $\left(180^{\circ}\right)$, pictures with higher magnification were taken in steps of $1 \mathrm{~mm}$ in welding direction, beginning at the start of the weld seam at $x=0 \mathrm{~mm}$. Although a wavy interface was present at both material combinations, the height of the waves was increased approximately by a factor of six, in case the aluminum flyer was replaced by a copper flyer with adapted charging energy. This is a result of the higher density and impact velocity that lead to an increase of the introduced kinetic energy. Both material combinations exhibited mixed zones, either on the top of the steel height or in the pockets between two heights, when joined with copper or aluminum, respectively. This finding might be attributed to the density of the joining partners, which are almost identical for copper/ steel and differ significantly for aluminum/steel.

In order to proof the tightness of the joint, the part was shock cooled from room temperature to $77 \mathrm{~K}$ and heated up again afterwards. This cycle was repeated 15 times. The leak tightness was demonstrated with an inner pressure of approximately $10^{-2}$ mbar at both temperature levels.

\section{Conclusions}

This manuscript describes two strategies which improve the fusion formation and as a consequence the joining mechanism during MPW of dissimilar metals. Firstly, an additional heat source is created at the joining interface by the help of a nickel interlayer on the steel parent. During the high-speed collision

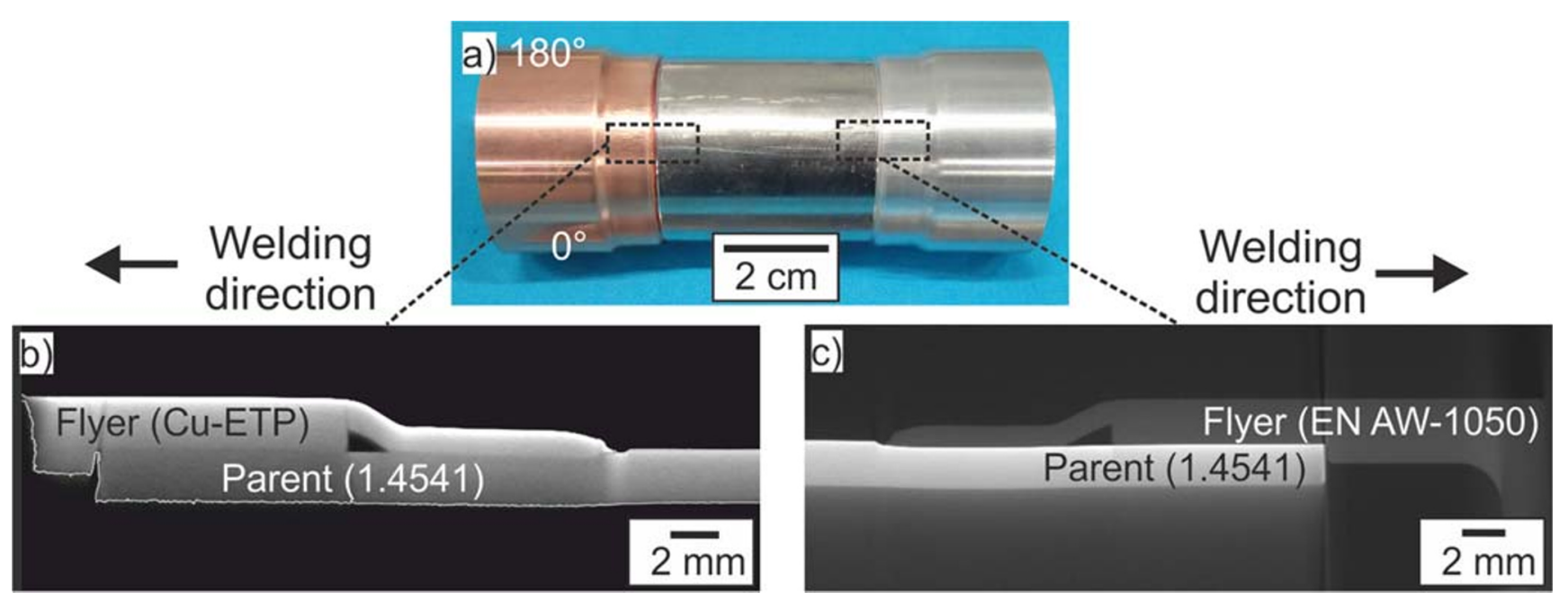

Fig. 6 a Multi-material part after MPW and X-ray computed tomography at the $\mathbf{b}$ copper-steel joining zone, and $\mathbf{c}$ aluminum-steel joining zone with the system FF35 CT from the company YXLON 

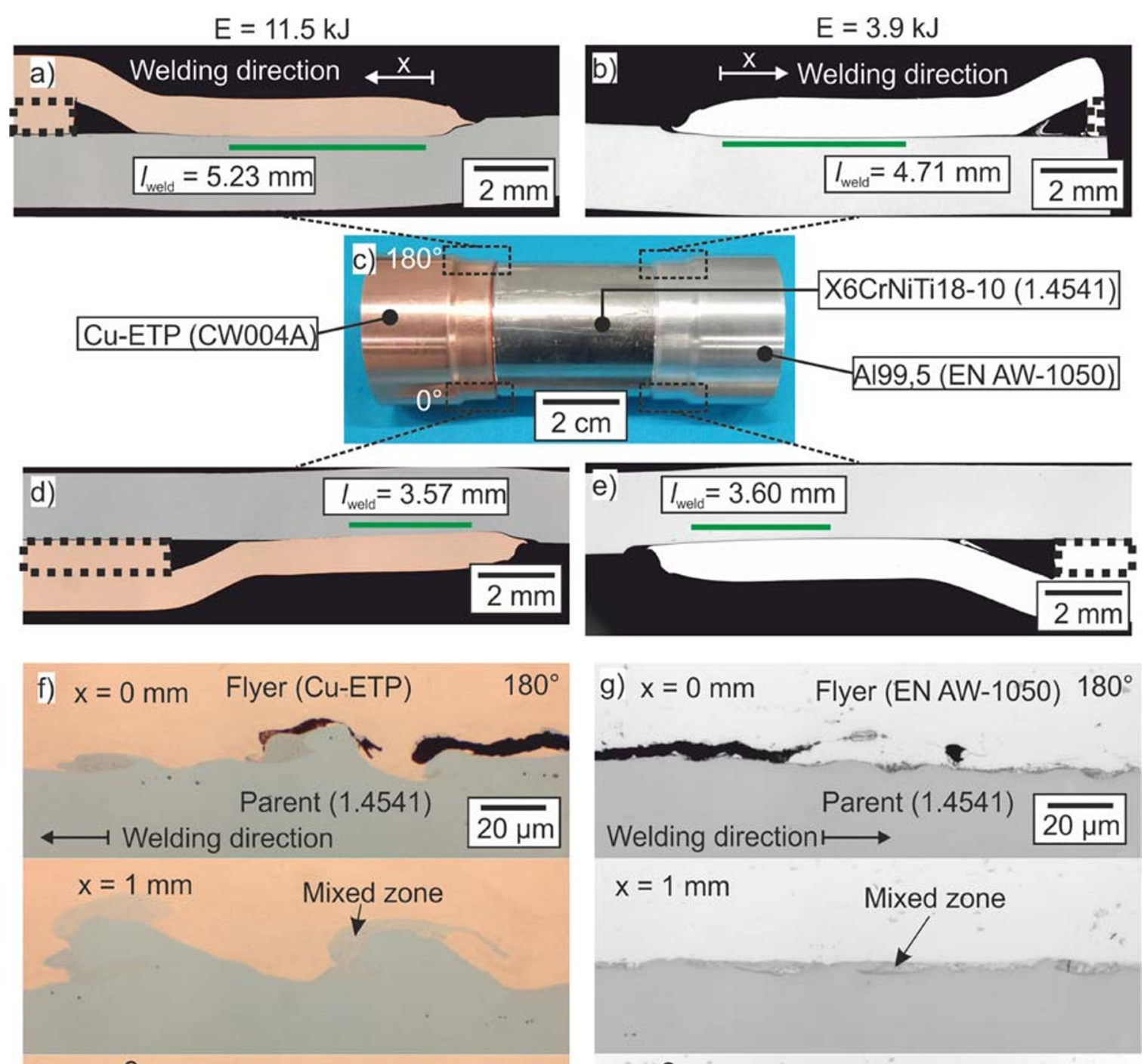

$\mathrm{x}=2 \mathrm{~mm}$

$\mathrm{x}=2 \mathrm{~mm}$

$\mathrm{x}=5 \mathrm{~mm}$

$\mathrm{x}=6 \mathrm{~mm}$

net $\rightarrow$

Fig. 7 a, b, d, e Polished cross sections of the magnetic pulse welded multi-material part in $\mathbf{c}$ and indication of the grooves for optical access of the flash measurement system at the samples for parameter adjustment

with dotted lines and details of selected positions $x$ of the weld interfaces between $\mathbf{f}$ copper and steel and $\mathbf{g}$ aluminum and steel with distinct differences in the waviness of the bond interface 


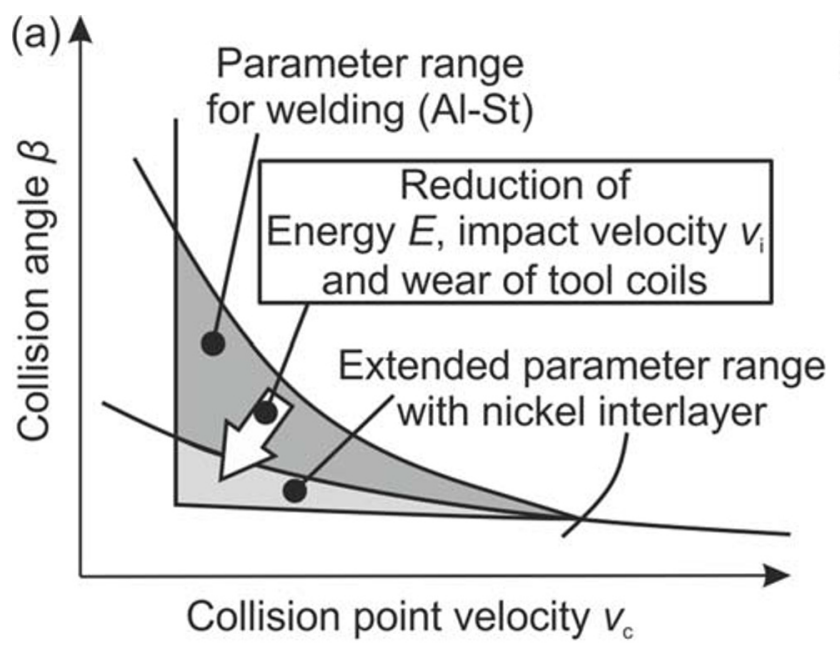

(b)

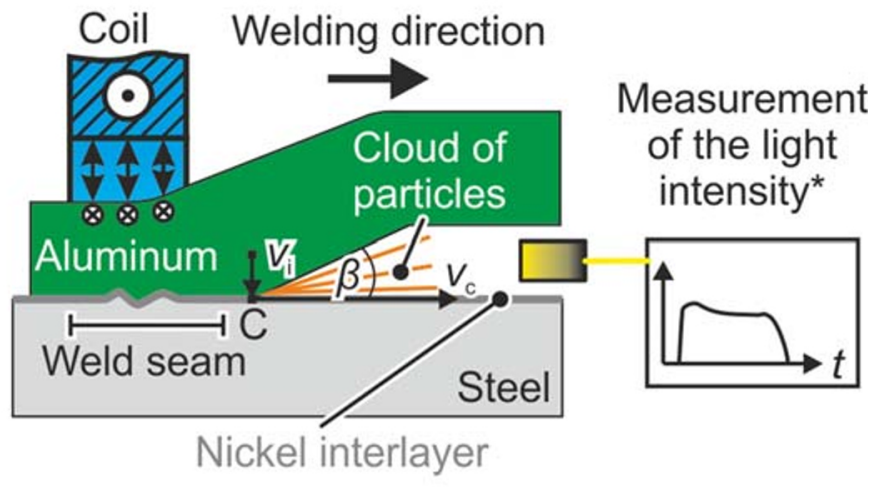

*DE 102016217758 B3, WO 2018/050569 A1

Fig. 8 a Schematic of the collision welding window according to [7] for aluminum and steel, extended with a nickel interlayer and b welding setup including the flash measurement system for the identification and adjustment of the collision kinetics

with the aluminum flyer, an exothermic reaction between aluminum and nickel produces heat and leads to longer weld seams compared to the material system aluminum and steel at a certain impact velocity. Conversely, this means that the initial impact velocity can be reduced to produce a weld seam with a certain length, see Fig. 8a. Secondly, a measurement system is applied, that evaluates the characteristic impact flash and helps to identify suitable joining parameters. According to the theory of the ejected cloud of particles and its contribution to the surface activation of the joining partners, the system is applied to obtain small collision angles $\beta$, see Fig. 8b.

In both applications, weld seams between dissimilar materials were generated and successfully tested under specific loading conditions. The driveshaft-like parts composed of aluminum and steel underwent torsional testing. They showed higher load-bearing capabilities in static and cyclic tests, compared to laser welded samples composed of aluminum. The second application was a part that consists of copper, aluminum, and steel. It was formerly joined by four electron beam welds. Here, MPW enabled a significant simplification of the assembly and guaranteed gas tight connections even after certain cooling and heating cycles. During all MPW trials, the flash measurement system enabled a parameter adjustment at the lower process boundary. Thus, the thermal and mechanical shock loadings on the tool coil as well as the energy consumption for the generation of the welds could be reduced.

Acknowledgments Open Access funding enabled and organized by Projekt DEAL. We would like to thank Dr. Juergen Peters from the Research Neutron Source Heinz Maier-Leibnitz (FRM II) at the Technical University of Munich for his readiness to discuss the results of the multi-material part welded with MPW technology. The authors would like to express their thanks to the colleagues from the competence field materials characterization and testing at Fraunhofer IWS for the sample preparation.
Authors' contributions Conceptualization: Joerg Bellmann; Methodology: Joerg Bellmann, Sebastian Schettler; Formal analysis and investigation: Joerg Bellmann, Sebastian Schettler; Writing - original draft preparation: Joerg Bellmann; Writing - review and editing: Sebastian Schulze, Markus Wagner,

Jens Standfuss, Martina Zimmermann, Eckhard Beyer, Christoph Leyens; Funding acquisition: Martina Zimmermann, Eckhard Beyer, Christoph Leyens; Resources: Martina Zimmermann, Eckhard Beyer, Christoph Leyens; Supervision: Martina Zimmermann, Eckhard Beyer, Christoph Leyens.

Funding The research was supported by the German Research Foundation within the subproject A1 "Magnetic pulse welding: Targeted manipulation of weld seam" which was part of the priority program 1640 "Joining by plastic deformation", grant number BE 1875/30-3.

Data availability Data and material are stored at Fraunhofer IWS and Research Neutron Source Heinz Maier-Leibnitz (FRM II) at the Technical University of Munich.

\section{Compliance with ethical standards}

Conflict of interest The authors declare that they have no conflict of interest.

Open Access This article is licensed under a Creative Commons Attribution 4.0 International License, which permits use, sharing, adaptation, distribution and reproduction in any medium or format, as long as you give appropriate credit to the original author(s) and the source, provide a link to the Creative Commons licence, and indicate if changes were made. The images or other third party material in this article are included in the article's Creative Commons licence, unless indicated otherwise in a credit line to the material. If material is not included in the article's Creative Commons licence and your intended use is not permitted by statutory regulation or exceeds the permitted use, you will need to obtain permission directly from the copyright holder. To view a copy of this licence, visit http://creativecommons.org/licenses/by/4.0/. 


\section{References}

1. Zhang Y, Babu SS, Prothe C, Blakely M, Kwasegroch J, LaHa M, Daehn GS (2010) Application of high velocity impact welding at varied different length scales. J Mater Process Technol. https://doi. org/10.1016/j.jmatprotec.2010.01.001

2. Philipchuk V, Scituate N, Roy LF (1962) Explosive Welding (US Patent 3,024,526)

3. Vivek A, Hansen SR, Liu BC, Daehn GS (2013) Vaporizing foil actuator: A tool for collision welding. J Mater Process Technol 213(12):2304-2311. https://doi.org/10.1016/j.jmatprotec.2013.07. 006

4. Wang H, Vivek A, Wang Y, Taber G, Daehn GS (2016) Laser impact welding application in joining aluminum to titanium. $\mathrm{J}$ Laser Appl 28(3):32002. https://doi.org/10.2351/1.4946887

5. Psyk V, Scheffler C, Drossel W-G, Kolchuzhin V, Mehner J, Faes K, Zaitov O, van Bossche Ad, Bozalakov D (2014) Advanced coil design for electromagnetic pulse technology - report on the methodology of coil design. Ergebnisse des Vorhabens der industriellen Gemeinschaftsforschung (IGF) gefördert über die Arbeitsgemeinschaft industrieller Forschungsvereinigungen e.V. EFB-Forschungsbericht, Bd 397. Europ. Forschungsges. für Blechverarbeitung, Hannover

6. Bellmann J, Lueg-Althoff J, Schulze S, Gies S, Beyer E, Tekkaya AE (2017) Measurement of collision conditions in magnetic pulse welding processes. Journal of Physical Science and Application 7(4):1-10. doi:https://doi.org/10.17265/2159-5348/2017.04.001

7. Carpenter SH, Wittmann RH (1975) Explosive welding. Annu Rev Mater Sci 5:177-199

8. Cuq-Lelandais J-P, Ferreira S, Avrillaud G, Mazars G, Rauffet B (2014) Magnetic Pulse Welding: welding windows and high velocity impact simulations. Huh H, Tekkaya AE (eds) ICHSF2014. Proceedings of the 6th International Conference on High Speed Forming, 26th-29th May 2014, Daejeon, Korea, pp 199-206

9. Jäger A, Tekkaya AE (2012) Online measurement of the radial workpiece displacement in electromagnetic forming subsequent to hot aluminum extrusion. In: Tekkaya AE, Daehn GS, Kleiner M (Hrsg) ICHSF 2012. Proceedings of the 5th international conference on high speed forming, S 13-22

10. Cuq-Lelandais J-P, Ferreira S, Avrillaud G, Mazars G, Rauffet B (2014) Magnetic pulse welding: welding windows and high velocity impact simulations. In: Huh H, Tekkaya AE (Hrsg) ICHSF2014. Proceedings of the 6th international conference on high speed forming, S 199-206

11. Bellmann J, Lueg-Althoff J, Schulze S, Hahn M, Gies S, Beyer E, Tekkaya AE (2019) Thermal effects in dissimilar magnetic pulse welding. Metals 9(3):348. https://doi.org/10.3390/met9030348

12. Böhme M, Sharafiev S, Schumacher E, Böhm S, Wagner MFX (2019) On the microstructure and the origin of intermetallic phase seams in magnetic pulse welding of aluminum and steel. Mater Werkst 50:958-964. https://doi.org/10.1002/mawe.201900034

13. Zakharenko ID, Sobolenko TM (1971) Thermal effects in the weld zone in explosive welding. Combust Explos Shock Waves 7(3): 373-375. https://doi.org/10.1007/BF00742828

14. Bataev IA, Lazurenko DV, Tanaka S, Hokamoto K, Bataev AA, Guo Y, Jorge AM (2017) High cooling rates and metastable phases at the interfaces of explosively welded materials. Acta Mater 135: 277-289. https://doi.org/10.1016/j.actamat.2017.06.038

15. Deribas AA, Zakharenko ID (1974) Surface effects with oblique collisions between metallic plates. Translated from Fisika Goreniya I. Vzyva (Vol. 10 No 3):409-421
16. Pabst C, Groche P (2018) Identification of process parameters in electromagnetic pulse welding and their utilisation to expand the process window. Int J Mater Mech Manuf 6(1):69-73

17. Koschlig M, Veehmayer M, Raabe D (2008) Production of steellight metal compounds with explosive metal cladding. In: Kleiner M, Tekkaya AE (Hrsg) ICHSF2008. Proceedings of the 3rd international conference on high speed forming, S 23-32

18. Bellmann J, Ueberschär F, Lueg-Althoff J, Schulze S, Hahn M, Beyer E, Tekkaya AE (2019) Effect of the forming behavior on the impact flash during magnetic pulse welding of tubes. In: Korkolis YP, Kinsey BL, Knezevic M, Padhye N (Hrsg) Proceedings of NUMIFORM 2019. The Minerals, Metals \& Materials Society (TMS), Pittsburgh, PA, USA, S 651-654

19. Bellmann J, Lueg-Althoff J, Niessen B, Böhme M, Schumacher E, Beyer E, Leyens C, Tekkaya AE, Groche P, Wagner MF-X, Böhm $S$ (2020) Particle ejection by jetting and related effects in impact welding processes. Metals 10(8). https://doi.org/10.3390/ met10081108

20. Ghosh P, Patra S, Chatterjee S, Shome M (2018) Microstructural evaluation of magnetic pulse welded plain carbon steel sheets. $\mathrm{J}$ Mater Process Technol 254:25-37. https://doi.org/10.1016/j. jmatprotec.2017.11.012

21. Bellmann J, Lueg-Althoff J, Schulze S, Gies S, Beyer E, Tekkaya AE (2016) Measurement and analysis technologies for magnetic pulse welding. Established Methods and New Strategies. Adv Manuf (4):322-339. https://doi.org/10.1007/s40436-016-0162-5

22. Bellmann J (2016) Verfahren und Vorrichtung zur Prozessüberwachung bei einer mittels Kollisionsschweißen gebildeten Schweißnaht, German patent granted under number DE 102016217758 B3

23. Bellmann J (2019) Method and device for monitoring the process for a welding seam formed by means of collision welding US 2019/ 0202009 A1

24. Bellmann J, Lueg-Althoff J, Schulze S, Gies S, Beyer E, Tekkaya AE (2018) Parameter identification for magnetic pulse welding applications. Key Eng Mater 767:431-438. https://doi.org/10.4028/ www.scientific.net/KEM.767.431

25. Bellmann J, Beyer E, Lueg-Althoff J, Gies S, Tekkaya AE, Schettler S, Schulze S (2017) Targeted weld seam formation and energy reduction at magnetic pulse welding (MPW). Biuletyn Instytutu Spawalnictwa 2017(5):91-102. https://doi.org/10.17729/ ebis.2017.5/10

26. Bellmann J, Lueg-Althoff J, Schulze S, Gies S, Beyer E, Tekkaya $\mathrm{AE}$ (2018) Effects of reactive interlayers in magnetic pulse welding. In: Daehn GS, Tekkaya AE (eds) Proceedings of the 8th International Conference on High Speed Forming, 13th-16th May 2018, Columbus, OH, USA

27. Ma E, Thompson CV, Clevenger LA, Tu KN (1990) Selfpropagating explosive reactions in $\mathrm{Al} / \mathrm{Ni}$ multilayer thin films. Appl Phys Lett 57(12):1262-1264. https://doi.org/10.1063/1. 103504

28. Bellmann J, Lueg-Althoff J, Schulze S, Hahn M, Gies S, Beyer E, Tekkaya AE (2019) Effect of the wall thickness on the forming behavior and welding result during magnetic pulse welding. Mater Werkst 212:150. https://doi.org/10.1002/mawe.201900024

29. Seeberger (2016) Datasheet AlMgSi (EN AW-6060). http:// wwwseebergernet/assets/pdf/werkstoffe/aluminium/de/ AlMgSipdf Zugegriffen: 18. Februar 2020

30. Seeberger Datasheet 3.0255 (EN AW-1050A). https://seeberger. net/_assets/pdf/werkstoffe/aluminium/de/3.0255.pdf. Zugegriffen: 23. Januar 2020 
31. Metalcenter Group (2020) Data sheet EN Cu-ETP/CW004A. https://wwwmetalcentergroupcom/media/4293/etp-cw004apdf Zugegriffen: 03. Juli 2020

32. Günther, Schramm (2020) Datasheet C45 (1.0503). https://www. gs-stahl.de/images/C45.pdf. Zugegriffen: 18. Februar 2020

33. Deutsche Edelstahlwerke (2015) Werkstoffdatenblatt X6CrNiTi18-10 1.4541. https://www.dew-stahl.com/fileadmin/ files/dew-stahl.com/documents/Publikationen/ Werkstoffdatenblaetter/RSH/1.4541_de.pdf. Zugegriffen: 03. Juli 2020

34. Faes K (2011) Tube welding. Belgian Welding Institute https:// wwwbil-ibsbe/sites/default/files/publicaties/andere/tube_welding_rev 7pdf Zugegriffen: 28. Januar 2020

35. Lueg-Althoff J, Bellmann J, Gies S, Schulze S, Tekkaya AE, Beyer E (2016) Magnetic pulse welding of tubes: ensuring the stability of the inner diameter. In: Otero V (ed) Euro-Asian Pulsed Power Conference \& Conference on High-Power Particle Beams 2016 Proceedings, 18th-22nd September 2016, Estoril, Portugal

36. Faes K, Waele D (2019) Electromagnetic Pulse welding of tubular products. Influence of process parameters and workpiece geometry on the joint characteristics and investigation of suitable support systems for the target tube. Metals 9(5):514. https://doi.org/10. 3390/met9050514

37. Bellmann J, Kirchhoff G, Lueg-Althoff J, Schulze S, Gies S, Beyer E, Tekkaya AE (2016) Magnetic pulse welding: joining within microseconds - high strength forever. In: American Welding Society and Japan Welding Society (ed.) Proceedings of the 10th International Conference on Trends in Welding Research and 9th International Welding Symposium of Japan Welding Society, 11th14th October 2016, Tokyo, Japan, pp. 91-94

38. Lueg-Althoff J, Bellmann J, Gies S, Schulze S, Tekkaya AE, Beyer E (2018) Influence of the flyer kinetics on magnetic pulse welding of tubes. J Mater Process Technol 262:189-203. https://doi.org/10. 1016/j.jmatprotec.2018.06.005

Publisher's note Springer Nature remains neutral with regard to jurisdictional claims in published maps and institutional affiliations. 